\title{
Participatory communication for tuberculosis control in prisons in Bolivia, Ecuador, and Paraguay
}

\author{
Silvio Waisbord ${ }^{1}$
}

Suggested citation

Waisbord S. Participatory communication for tuberculosis control in prisons in Bolivia, Ecuador, and Paraguay. Rev Panam Salud Publica. 2010;27(3):168-74.

ABSTRACT Objectives. To assess the challenges in reducing tuberculosis (TB) in prisons in Bolivia, Ecuador, and Paraguay and propose ways to address them through communication interventions. Methods. Challenges to two central goals of TB control - early diagnosis of positive cases and successful application of the directly observed treatment, short course (DOTS) strategywere examined. Data were gathered (through in-depth, structured interviews) and focus groups were conducted in the prisons that housed the largest number of male inmates in each country. Interviewees and focus group participants included program directors, administrative personnel, correctional health and security staff, and incarcerated people who were or had been under treatment for TB and had participated as "peers" in health services.

Results. The findings showed a range of entrenched obstacles for adequate TB control. Stigmatizing attitudes and low knowledge about TB among inmates and key prison personnel discouraged people living in prisons from seeking diagnosis and treatment. Systemic problems in prison health services, along with squalid living conditions, lack of coordination between national TB programs and prison health systems, and insufficient allocation of resources to health prevented the provision of adequate TB prevention and care.

Conclusion. In addressing the barriers to effective TB control in prison systems in Bolivia, Ecuador, and Paraguay, a participatory approach to communication is necessary.

Key words Health communication; vulnerable populations; Health of Specific Groups; tuberculosis; prisons; Bolivia; Ecuador; Paraguay.

Tuberculosis (TB) is one of the most important and urgent challenges to global health care structures. The resurgence of the disease in the past few decades has renewed the attention of governments, international agencies, donors, and affected communities to-

\footnotetext{
George Washington University, School of Media and Public Affairs, Washington, DC, United States of America. Send correspondence to: Silvio Waisbord, School of Media and Public Affairs, George Washington University, 805 21st Street NW, Suite 400, Washington, DC 20052, USA; e-mail: waisbord@ gwu.edu
}

ward TB and revitalized their efforts to prevent and control it. TB disproportionately affects populations already suffering from poverty and social exclusion, with an estimated $95 \%$ of TB cases and $98 \%$ of TB-related deaths occurring in the developing world $(1,2)$.

Incarcerated communities are among the populations most vulnerable to TB. Several studies have concluded that TB rates in prisons are typically between 10 to 100 times higher than among the general population $(3,4)$. Rates of multidrug-resistant tuberculosis (MDR-TB) as well as HIV-TB coinfection are also higher in prisons. There are a variety of reasons for such patterns. First, as mentioned above, TB mostly affects the poor, who represent the majority of incarcerated people worldwide. In addition, substandard prison living conditions, including poor nutrition, overcrowding, and lack of ventilation, plus the ongoing influx of new inmates, make prisons ideal "reservoirs" for the propagation of TB. Management and treatment of TB cases in prisons is more difficult than in the general population due to these chal- 
lenges, particularly in the developing world. Studies have also concluded that prison settings are especially difficult for TB detection and care $(5,6)$. Addressing these obstacles to ensure effective control of TB in correctional facilities and help prevent the spread of the disease to the general population is a global priority.

In principle, the implementation of the directly observed treatment, short course (DOTS) strategy endorsed by the World Health Organization (WHO) and the Stop TB Partnership should be relatively easier to implement in prisons than in the general population. Because they serve a captive population, prison health services should be able to conduct the regular examinations and active case detection advocated by DOTS with relative ease. TB screening and diagnosis could be performed as part of inmates' admittance to prison, followed up with regular checkups. With efficient diagnosis, plus a reliable drug supply, and well-trained human resources, penitentiaries could provide effective TB services. The reality of most prison systems, however, falls short of this potential. Several studies have documented that the lack of safe water and appropriate food for inmates under treatment, widespread violence and insecurity, corruption, and underfunded health services are some of the most notorious obstacles for the successful implementation of DOTS in prisons $(7,8)$.

For successful control of TB, multiple and coordinated interventions are needed to address the entrenched constraints of health services in the majority of prison systems in the developing world. Given the complexity of these constraints, no "magic bullet" is likely to provide effective and sustainable results. Based on evidence from recent interventions in prisons in Eastern Europe and Central Asia, several authors have concluded that there are no quick or easy solutions to properly address the numerous obstacles to controlling the disease in penitentiary systems (9-12).

Several studies conducted in Latin America have documented constraints to TB control in prisons that largely mirror those found in other parts of the developing world (13-15), and WHO estimates the rate of $\mathrm{TB}$ in the region is more than 22 times higher among people living in prisons than among the general population (16). These constraintssqualid living conditions, inadequate health services, and persistent safety problems, combined with the low socioeconomic background of the majority of inmates, another risk factor for the disease-require innovative and complementary approaches.

As part of its regional strategy for TB control, the Pan American Health Organization (PAHO) fostered a comparative study on challenges for TB control in male prisons in Bolivia, Ecuador, and Paraguay. The purpose of the study was twofold: to assess the existing challenges for reducing TB in prisons, focusing on those that undermined early diagnosis of positive TB cases and the successful application of DOTS, and to propose ways that they could be addressed through communication interventions.

The research also explored how TB control in prisons might be improved using communication, as per the definition below espoused by the World Congress on Communication for Development:

[Communication is] a social process based on dialogue using a broad range of tools and methods. It is also about seeking change at different levels, including listening, building trust, sharing knowledge and skills, building policies, debating and learning for sustained and meaningful change (17: 3).

Although extensive research has been conducted on health communication issues in developing countries, particularly with regard to immunization, reproductive health, and HIV/AIDS programs, only a few studies have been conducted on the role of communication in $\mathrm{TB}$ control among both the general and incarcerated populations (18).

This article describes the findings of the study conducted in male prisons in the three countries and discusses their implications for research and practice in communication for TB control as well as for health communication.

\section{MATERIALS AND METHODS}

The study gathered the data through two sets of qualitative methodologies: in-depth, structured interviews (IDIs) and focus group discussions (FGDs). Open-ended questionnaires were used in both the IDIs and the FGDs, and all interviews and discussions were transcribed. The rationale for the selection of these methods was twofold. One reason was conceptual: the project aimed to determine how TB is perceived and experienced within the overall context of living conditions in prisons, and qualitative methods offered appropriate instruments for assessing knowledge and attitudes about $\mathrm{TB}$, the richness and complexity of living and working in prisons, and the functioning of health services. The other reason was logistical: it was difficult to design and implement a quantitative study to be administered to a representative sample in the prison. Given access and safety problems, prison and health authorities discouraged the suggestion of distributing or administering questionnaires that would involve large numbers of inmates.

The selected sites in all three countries were the prisons with the largest number of male inmates. In Bolivia, the selected study site was the San Pedro prison, which has an estimated population of about 1 500. Guayaquil's Social Center for Rehabilitation, with a population of about 6 000, was selected in Ecuador. In Paraguay, the chosen site was the prison in Tacumbú, which houses more than 6000 people. To meet the goals of the study, a wide range of sources was selected to obtain the broadest possible perspective. IDIs and FGDs were conducted with program directors, administrative personnel, correctional health and security staff, and incarcerated people who were or had been under treatment for TB and had participated as "peers" in health services. Because the goal was to gather information from key stakeholders about TB issues, the study did not obtain a sample representative of the entire inmate population in each prison. Participants were identified through professional consensus among the directors of the prison health services and the selected penitentiary. The size of the sample was comparable: 28 interviews were conducted in Paraguay, 33 in Bolivia, and 37 in Ecuador. All interviews were conducted during the second semester of 2007. As the principal investigator of the study, the author designed and coordinated the training of interviewers as well as data gathering and analysis in all three countries. PAHO funded the study, collaborated with the National Tuberculosis Program (NTP) and the penitentiary health system in each country in its design and site selection, and provided logistical support during the fieldwork. 


\section{RESULTS}

The findings revealed a troubling picture of the quality of TB care in prisons and the numerous constraints at both the individual-social level and the structuralsystemic level (the prison and health system).

\section{Individual-social level}

The study explored knowledge and attitudes among incarcerated populations and correctional personnel to identify obstacles to timely care-seeking and diagnosis. The findings confirmed the conclusions of previous studies conducted in prisons that indicated inmates have limited information about TB symptoms and transmission $(19,20)$. For example, while many interviewees correctly identified coughing as a form of transmission, they also incorrectly mentioned sharing silverware, cigarettes, drugs, alcohol, and "tereré" (a popular herbal drink in Paraguay that is shared and sipped through a metal straw) as potential means of spreading the disease. Only a few study participants identified covering the mouth when sneezing or wearing a mask as appropriate methods of reducing the chances of transmission. Most inmates believed TB symptoms were similar to those of the common cold and failed to identify persistent cough, fever, night sweats, weight loss, and shortness of breadth as possible TB symptoms. Several inmates who had completed or were undergoing treatment said they did not receive basic information about TB symptoms and care when they were originally diagnosed with the disease. The following quote from a Paraguayan inmate reflects the typical knowledge gap found among interviewees: "I had a cough. I was very thin, and I ate very little. I was barely able to walk. Yet I didn't ask for help, because I didn't know I could have TB."

In addition to a lack of knowledge, the study found two sets of attitudes that deterred inmates from seeking TB care: low prioritization of health status, and pervasive stigma about TB. As argued in previous studies (21), health care-seeking decisions in the prisons were embedded in the webs of relationships and expectations that existed among the inmates and security personnel. Low priority was given to TB care or any other type of health care. Both inmates and health staff admitted that they had a "low interest in health" and observed that people generally sought health care only when they couldn't function "normally." Several health staff observed that inmates gave higher priority to other issues, namely their legal status (a significant percentage of inmates hadn't received a sentence), visits from spouse and relatives, and prison safety. Given these other concerns, inmates tended to avoid any behaviors, such as seeking health care, that might negatively affect their existence in the penitentiary (e.g., by forcing the cancellation of family visits). They preferred to hide health conditions that, in their mind, could compromise their social status, safety, or penitentiary privileges.

For example, based on the interviews, many inmates were reluctant to be publicly recognized as a "sick person." They feared that if they were labeled as "sick," cellmates and security guards might treat them differently (e.g., in a disparaging manner). Many believed being identified as sick could endanger their work status (e.g., eliminating them from more desirable positions that might require physical stamina) or their social status (e.g., reducing their general acceptance by cellmates). Prison leadership roles, which offer respect and recognition, are based on masculinity criteria such as physical strength. As in past research (22), the interview responses indicated sickness runs contrary to dominant ideals of male identity in prison settings; seeking health care can convey weakness and imply the inability to fulfill prevailing gender roles. Patterns in health care-seeking behavior among male inmates were similar to those revealed among the general male population, indicating delays in seeking TB care are related to embedded notions about conventional masculinity and health, as found in other research conducted in the developing world (23).

Many interviews also indicated that inmates gave a low priority to health issues because they did not expect much benefit from prison health care services. As one Ecuadorian inmate described it, "[inmates] don't expect much from the [prison] system." They assumed that the prison would not provide adequate care, and that the correctional staff was not concerned about their well-being. In general, they didn't trust anyone. Only when certain health conditions affected their daily activities were they likely to ask for help. Several inmates infected with TB said they only sought help when they could no longer conduct their normal daily routines or coughed up bloodtinged phlegm.

Another set of attitudes that discouraged inmates from seeking timely health care stemmed from the pervasive stigma toward people infected with $\mathrm{TB}$, which is associated with death and personal danger. Without exception, all interviewees stated that inmates were often reluctant to be tested for TB or any other health condition (particularly HIV) because they were concerned about the possible repercussions. According to health staff, inmates failed to distinguish between TB and HIV, fearing and stigmatizing them equally. Inmates' concerns about being tested for the two diseases were rooted in fears about the possible effects of revealing a positive status, such as social isolation, health workers refusing to provide care, and physical attacks. Inmates were also concerned about attitudes toward TB among their relatives. They feared that if family members knew they had contracted TB they might stop visiting them. The following testimony from a Paraguayan inmate illustrates such concerns: "I didn't know anything about TB. I called my sister ... and told her what was happening. I was ashamed to tell her. I asked her not to tell anyone, not even my mother. I started to cry because I felt people would stay away from me. One of my cellmates told me we had to be apart, that we couldn't use the same things."

Evidence that the combination of lack of knowledge, low prioritization of health, distrust of prison services, and fear of stigmatizing behaviors deterred inmates from finding out about their health status and seeking care suggests that increasing knowledge about symptoms, transmission, and care may not be sufficient to prompt inmates to seek treatment for TB. It may also be necessary to address other determinants of health care-seeking decisions grounded in social/power relationships and perceptions of masculinity among inmates and security personnel.

\section{Prison and health system}

The current findings also suggest it would be shortsighted to assume that barriers to and responsibility for TB care- 
seeking lie primarily among inmates. The study found that TB services for inmates are beset by numerous problems rooted in the functioning of both the prison and health systems. As an Ecuadorian penitentiary official described it, "the problem of TB care is not only medical; it is linked to the whole system."

According to the study results, severe obstacles stemmed from the lack of institutional coordination among different units with regard to the health care of incarcerated populations. One basic problem was that, at the time of the research, prison health services were not within the jurisdiction of the Ministry of Health in any of the countries studied. This problem has since been addressed in Ecuador, but coordination constraints remain. In all three countries, there is weak coordination between the NTP, which is a unit of the Ministry of Health, and the Ministry of Justice (or its equivalent), which oversees the penitentiary system. This gap makes it difficult for prison health services to collaborate with the NTP, even though they follow the protocols established by it. This lack of interagency coordination undermines the possibility of maximizing the strengths of various units in specific activities, such as diagnosis procedures (e.g., sample collection and transportation, lab analysis and equipment, $x$-rays) and case treatment (referral of released patients, drug supply, supervision). In addition, there is insufficient coordination between TB and HIV/AIDS services in prisons. This gap is particularly alarming considering the fact that TB is a common opportunistic infection among people living with HIV/AIDS. It also represents a lost opportunity for collaboration between the two programs on the provision of diagnosis and care.

Likewise, linkages between prison health services and national health systems, and among health services within the prison system itself, are, at best, tenuous. For example, there are no established, institutionalized linkages between prison health services and nearby national or provincial clinics and hospitals, or among the health services of various prisons. This lack of adequate coordination undermines the possibility for collaboration in the provision of diagnosis and care and the establishment of a well-functioning referral system.

According to the study, inmates under treatment who are released or trans- ferred to another penitentiary are rarely adequately monitored and followed up. Interviewees cited many cases of former inmates who stopped or interrupted their treatment after their incarceration because they lost their prison health services registration card, did not know where to go to receive health care services outside the prison, or were afraid to attend community health clinics. Patient complacency was also a constraint. A Paraguayan nurse noted that many people under treatment while in prison default after their release because they do not seek out follow-up health care, "even when we give them the contact information." This situation is particularly worrisome given the problems of MDR-TB perpetuated by incomplete treatment.

The shortcomings of prison health systems make it difficult to provide quality services. This is a cause for concern considering evidence from several other studies conducted in Latin America and the Caribbean (24-27) that the combination of overcrowding, lack of ventilation and hygiene, and widespread consumption of illegal substances increases the likelihood that incarcerated people will contract TB and suffer poor health. Many testimonies from those interviewed in the current study confirm the findings of other research about the terrible conditions of prisons in the region. Statements such as "overcrowded prisons turns TB into a daily danger" and "TB is a time bomb in prisons" reflect the widespread sentiment of many different types of stakeholders that prison living conditions promote the spread of TB.

Prison health systems lack well-established TB control programs as well as the basic infrastructure to ensure the effective delivery of TB care. Epidemiological surveillance is weak due to staff shortages, insufficient drug supplies, and lack of safe access to prison blocks. Without good surveillance, it is impossible to maintain the up-to-date, comprehensive records on inmates' health conditions that are required to support active case finding as well as early diagnosis and treatment. Prison laboratories are either nonexistent or insufficiently equipped to comply with diagnosis procedures, often lacking basic inputs needed to obtain sputum samples and perform required tests. Prison health services also lack a sufficient and reliable drug supply to ensure that all inmates who test positive for TB start treatment immediately. In addition, due to the lack of space, inmates with a positive diagnosis for TB are often isolated from the general prison population in improvised rooms that lack ventilation and house non-TB patients who are either suffering from other health conditions or waiting for other types of care.

One of the most alarming consequences of substandard TB programs in prisons is poor record-keeping and the lack of regular observance of basic policy and procedures for prevention, care, and control of the disease. Consequently, as one prison health official in Bolivia observed, "prison authorities and staff as well as external services and laboratory personnel do not have a clear idea about the number of people under treatment or the efficacy of detection of people with active TB." There are also significant problems with the quality of laboratory specimens due to delays in the delivery of samples taken at the prison infirmary and the lack of adequate storage equipment. Normative procedures for screening out patients and collecting and delivering samples are not strictly followed. In the Guayaquil prison, for example, sputum samples were only collected once a week due to staff shortages and inadequate communication among the various prison units involved in health care services. Due to the lack of adequate refrigeration and the fact that samples were often left for days at room temperature, the quality of the samples was dubious when they arrived at the laboratory. In the focus groups, several health staff acknowledged that they were not familiar with normal data collection procedures and did not receive any training.

Rampant insecurity in prisons also affects TB services. Inmates are often reluctant to come to the infirmary to take the prescribed medication due to security concerns. One Ecuadorian health official estimated that "about $5 \%$ of [people under treatment] don't take their medication regularly because they can't or don't want to leave their cells." Another official explained that some patients "need to come from cell blocks that are far from the health room" but don't come because "they are fearful, receive threats, or lack money [to pay bribes to be taken to the health office]." Inmates fear that leaving their cell to receive health care services may reveal their condition to other inmates and thus result in physical violence. Authorities acknowledge that controlling violence among in- 
mates is not always possible. To address this problem, security staff are assigned to deliver drugs to inmates in their cells to ensure that they consistently follow the full course of treatment. However, this measure doesn't address other issues, such as the need for counseling-a vital support for those receiving $\mathrm{TB}$ treatment-or the discrimination and violence against inmates living with TB. Furthermore, officials expressed doubts about the effectiveness of utilizing security personnel to deliver drugs and ensure their correct intake (side effects often discourage TB patients from taking the drugs prescribed, particularly during the first weeks of treatment). Distrust between inmates and security staff often results in those under treatment refusing or pretending to consume TB drugs. Rampant corruption and other prison conditions, such as the sporadic violence that can make certain prison blocks inaccessible, even for armed personnel, can also create barriers to effective treatment. All of the above obstacles to regular drug intake increase the possibility of incomplete TB treatment and MDR.

The quality of prison health services is also undermined by human resource constraints. High levels of staff rotation are common due to low salaries and irregular payments, work overload, and low morale. Another constraint is fear of contracting the disease among health staff and social workers, who often expressed feelings of frustration and fatalism about the risk of working with inmates, reflected in the following testimonies from Ecuadorian interviewees: "I am afraid of MDR patients. I avoid going to work"; "I ask them to cover their mouth, but they don' $t$ "; "We are in fear because we have direct contact with patients. We only have God's protection."

As a result of this fear, the delivery of TB support services often depends on the efforts of part-time staff and volunteerswho typically lack even minimal knowledge of TB care and do not receive adequate training or have access to reference materials to support their work-and sometimes the inmates themselves. In the prisons in Ecuador and Paraguay, the inmates developed communication materials, organized talks, and produced skits to educate their peers about TB symptoms. Religious groups active in correctional facilities have also provided educational services to inmates. Support may also come from health staff (who have been known to purchase food or try to obtain donations from local stores) or inmates' relatives (who sometimes provide drugs to people under treatment). Interviewees also mentioned other types of outside support, such as ad hoc efforts organized by neighborhood associations and nongovernmental organizations (NGOs), and the personal commitment of health staff in hospitals in providing equipment and services (e.g., delivery of sputum samples and results, educational materials, and other types of supplies).

\section{DISCUSSION}

The findings of the current study confirm those from previous studies in various regions of the world (27-30) that found TB control in prisons is constrained by varied and entrenched obstacles. Stigma and violence discourage inmates from seeking care. Health checkups for new inmates and periodic examinations are rare. Prisons lack active detection strategies to identify cases. Health systems largely depend on the goodwill of health staff and inmates to offer educational talks and other activities to encourage early diagnosis. Prison health services are disconnected from the NTP and the national health system. Prisons lack basic infrastructure to isolate affected people and provide reliable and secure care. The overall improvement of prison living conditions is crucial not only for TB control but also for the improvement of health conditions overall. The "perfect storm" of overcrowded and squalid living conditions plus grave nutritional deficits and widespread drug abuse among inmates facilitates the spread of TB. The dire situation of $\mathrm{TB}$ reflects the larger problems of health and health care among incarcerated communities in the three countries.

One of the main implications of these findings is that the conventional tasks of communication are insufficient to address the many challenges of TB control. As suggested by a study conducted in Honduras (31), improving individual knowledge about TB symptoms, transmission, and care among inmates may have, at best, limited impact in promoting TB care-seeking behaviors. At worst, they may contribute to deepening frustration and disappointment by potentially drumming up demand for services that cannot be delivered on par with normative procedures and quality standards.
The magnitude of the challenges justifies the adoption of a conception of communication that emphasizes the participation of various stakeholders to address problems at both the individual-social and structural-systemic levels. In fact, testimonies from interviewees suggest that informal efforts of community participation have already been able to fill many gaps. What is needed is to go beyond ad hoc efforts motivated mainly by individual goodwill and approach community mobilization as a series of systematic and strategic efforts. Mobilization actions need to be two-pronged to tackle the obstacles identified in the analysis. One set of activities requires the participation of affected communities to tackle challenges at the individual-social level. A second set of interventions, including broad-based advocacy and policy dialogue, is needed to address problems in prison systems with the goal of strengthening the quality of TB care services, living conditions, and health systems.

The first set of activities is necessary to promote opportunities for communication and participation among key actors inside each penitentiary. Peer education and participatory design of informational activities (e.g., radio programs and skits produced within and outside of prisons) and reference materials may help initiate discussions about prejudice and correct misinformation about TB among health and security staff as well as inmates. By stimulating communication among various actors inside prisons, such activities can address misconceptions about TB transmission and care, reduce stigma, and increase trust of health services. They may also strengthen a sense of common purpose among inmates. A core notion of participatory communication in health is that affected communities play a central role through voicing concerns and demands as well as identifying and implementing actions. Such actions help to strengthen social ties and reduce solitary behavior and fatalistic attitudes among inmates and thus may increase their tendency to seek health care.

Broad-based advocacy is needed to address chronic and widespread problems in prison health systems that affect the quality of living conditions and health services. It requires the formation of multi-actor coalitions integrated by health and prison authorities and staff, TB activists, inmates and families, technical and professional associations, in- 
ternational organizations and donors, and NGOs. The goal is to strengthen the commitment of key decision-makers to TB control in penitentiaries and make it a health policy priority. Advocacy activities need to include the participation of officials who are in a position to facilitate better coordination between NTP and penitentiary health services and are responsible for earmarking resources and assigning personnel. This should help solve organizational and procedural problems such as the lack of comprehensive record-keeping and the lack of screening during prison admission. It could also improve the ability to trace and follow up people under treatment who are released or transferred, and minimize difficulties in collecting and transporting samples.

Raising awareness about poor living conditions (e.g., overcrowding, safety, and sanitation) and substandard health services in correctional facilities as well as their implications for effective TB control is a necessary first step. It is important to promote understanding of the fact that the TB situation in prisons affects the community at large, given the constant influx of people in and out of penitentiaries, among other factors. Educating officials about the dimension and impact of the TB problem is crucial for addressing the problems identified above-namely, the lack of coordination between prison health services and national health programs (including the NTP) - and an increased allocation of resources to prison health care services is required to avoid health staff shortages and improve record-keeping.
Success is possible if, as demonstrated in studies in Europe and Central Asia (32, 33), a combination of actions is designed and implemented at different levels with active participation from key players. Given the range of challenges found in the study, national TB and health service programs would be ill advised to approach communication programs only as a set of activities to increase knowledge about transmission, symptoms, and care among incarcerated populations. Such an approach is too narrow to modify health care decisions grounded in inmates' social context, and affected by the chronic problems of health services in penitentiary systems. TB control in prisons affects a broad set of actors, including incarcerated populations, family members, health and correctional staff, prison and health authorities, and local communities. Therefore, communication initiatives need to be approached as a participatory process of empowerment bringing together members of affected communities to discuss and identify appropriate courses of action and implement collective actions.

\section{Conclusions}

This study provided an assessment of the individual-social and structuralsystemic challenges that undermine current $\mathrm{TB}$ control efforts in prisons in three countries in Latin America, and proposed ways in which participatory communication could contribute to addressing obstacles. The findings and recommendations may not be entirely applicable to female prisons (given the well-known differences in health care-seeking behaviors between men and women, among other factors) or to prisons organized according to the principles of restorative justice, in which living conditions and health programs are largely better than the cases studied here. Strengthening TB programs requires participation from various actors to address the obstacles described above. Inclusive debates to assess problems and solutions along with peer education activities may contribute to addressing individual-social obstacles such as misconceptions about TB, stigma, and lack of interest in personal health among inmates. Joint programmatic collaboration between prison health services and national health programs; partnerships between prisons and other actors (e.g., foundations, faith-based groups, food providers, and transportation companies); and targeted advocacy among key authorities in various sectors (political, security, justice, and health) may help to address structural-systemic problems such as the lack of inter-unit coordination, staff shortages, poor living conditions, and insufficient resources to deliver adequate health services (from laboratory equipments to food) for people under treatment. Broad participation may be effective not only in targeting obstacles at the individual-social and structuralsystemic levels but also in helping to stimulate a sense of ownership among key stakeholders, an important criterion for long-term sustainability of effective communication interventions.

Acknowledgments. The author thanks Mirtha del Granado for her support and suggestions, and the staff of PAHO in the countries that participated in the project.

\section{REFERENCES}

1. Grange JM, Zumla A. The global emergency of tuberculosis: what is the cause? J R Soc Promot Health. 2002;122(2):78-81.

2. Dye C, Maher D, Weil D, Espinal M, Raviglione M. Targets for global tuberculosis control. Int J Tuberc Lung Dis. 2006;10(4):460-2.

3. Coninx R, Maher D, Reyes H, Grzemska M. Tuberculosis in prisons in countries with high prevalence. BMJ. 2000;320(7232):440-2.

4. Drobniewski F. Tuberculosis in prisonforgotten plague. Lancet. 1995;346(8980):948-9.

5. Lobato MN, Roberts CA, Bazerman LB, Hammett TM. Public health and correctional collaboration in tuberculosis control. Am J Prev Med. 2004;27(2):112-7.

6. Levy MH, Reyes H, Coninx R. Overwhelming consumption in prisons: human rights and tuberculosis control. Health Hum Rights. 1999; 4(1):167-91.
7. Greifinger RB, Bick J, Goldenson J, editors. Public health behind bars: from prisons to communities. Dobbs Ferry (NY): Springer; 2007.

8. Farmer P. The house of the dead: tuberculosis and incarceration. In: Mauer M, ChesneyLind $\mathrm{M}$, editors. Invisible punishment: the collateral consequences of mass imprisonment. New York: New Press; 2002.

9. Stern V. Sentenced to die? The problem of TB in prisons in Eastern Europe and Central Asia. London: International Centre for Prison Studies; 1999

10. Atun R, Olynik I. Resistance to implementing policy change: the case of Ukraine. Bull World Health Organ. 2008;86(2):147-54.

11. Lobacheva T, Asikainen T, Giesecke J. Risk factors for developing tuberculosis in remand prisons in St. Petersburg, Russia-a case-control study. Eur J Epidemiol. 2007;22(2):121-7.
12. Walcher G. Prisons as regional drivers of HIV/AIDS and tuberculosis in some Central Asian countries: a matter of 'least eligibility'? Int J Prison Health. 2005;1(2-4):103-15.

13. Barreto A, Biondi E, Larouze B. Prevalence of pulmonary tuberculosis and comparative evaluation of screening strategies in a Brazilian prison. Int J Tuberc Lung Dis. 2005;9(6):633-9.

14. Oliveira HB, Cardoso JC. Tuberculose no sistema prisional de Campinas, São Paulo, Brasil. Rev Panam Salud Publica. 2004;15(3):194-9.

15. Burattini M, Massad E, Rozman M, Azevedo RS, Carvalho H. Correlation between HIV and HCV in Brazilian prisoners: evidence for parenteral transmission inside prison. Rev Saude Publica. 2000;34(5):431-6.

16. World Health Organization. Guidelines for the control of tuberculosis in prisons. Geneva: WHO; 1998. 
17. The Communication Initiative; Food and Agriculture Organization of the United Nations; World Bank. World Congress on Communication for Development: lessons, challenges and the way forward. Washington: World Bank; 2007.

18. Waisbord S. Beyond the medical-informational model: recasting the role of communication in tuberculosis control. Soc Sci Med. 2007;65(10): 2130-4.

19. Woods GL, Harris SL, Solomon D. Tuberculosis knowledge and beliefs among prison inmates and lay employees. J Correctional Health Care. 1997;4(1):61-71.

20. Sanchez A, Gerhardt G, Natal S, Capone D, Espinola A, Costa W, et al. Tuberculosis prevention and control in large jails: a challenge to tuberculosis elimination. Am J Prev Med. 2006;30(2):125-30.

21. de Viggiani N. Unhealthy prisons: exploring structural determinants of prison health. Sociol Health Illn. 2007;29(1):115-35.

22. Evans T, Wallace P. A prison within a prison? The masculinity narratives of male prisoners. Men Masc. 2008;10(4):484-507.

23. Rintiswati N, Mahendradhata $Y$, Suharna, Susilawati, Purwanta, Subronto Y, et al. Jour- neys to tuberculosis treatment: a qualitative study of patients, families, and communities in Jogjakarta, Indonesia. BMC Public Health. 2009 May 27;9:158. doi: 10.1186/1471-2458-9-158.

24. Zárate E, Lobón I, Saavedra C, Castañeda M. Tuberculosis en nuevos escenarios: establecimientos penitenciarios. An Fac Med Lima. 2005;66(2):148-58.

25. Núñez Vega J. Cacería de brujos: drogas "ilegales" y sistema de cárceles en Ecuador. Quito: Facultad Latinoamericana de Ciencias Sociales Sede Ecuador; 2006.

26. Carranza E, Houed M, Liverpool N, Mora L, Manzanera L. Sistemas penitenciarios y alternativas a la prisión en América Latina y el Caribe. Buenos Aires: Depalma; 1992.

27. Observatorio Venezolano de Prisiones. A la sombra de la sociedad: situación penitenciaria en Latinoamérica 2007. Caracas: OVP; 2007.

28. Reyes H, Coninx R. Pitfalls of tuberculosis programmes in prisons. BMJ. 1997; 315(7120): 1447-50.

29. Reyes H. Pitfalls of TB management in prisons, revisited. Int J Prison Health. 2007;3(1): 43-67.

30. Harries AD, Nyirenda TE, Yadidi AE, Gondwe MK, Kwanjana JH, Salaniponi FM.
Tuberculosis control in Malawian prisons: from research to policy and practice. Int J Tuberc Lung Dis. 2004;8(5):614-7.

31. Mangan JM, Arias MS, Sierra T, Perez M, Medina RL, Yanez R. Evaluating the strengths and weaknesses of tuberculosis educational activities for prisoners in Honduras. Int J Tuberc Lung Dis. 2006;10(10):1152-8.

32. Rodrigo T, Caylà JA, García de Olalla P, Brugal MT, Jansà JM, Guerrero M, et al. Effectiveness of tuberculosis control programmes in prisons, Barcelona 1987-2000. Int J Tuberc Lung Dis. 2002;6(12):1091-7.

33. Godinho J. Stopping tuberculosis in Central Asia: priorities for action. Washington: World Bank; 2005.

Manuscript received on 6 September 2009. Revised version accepted for publication on 19 November 2009.

RESUMEN Objetivos. Identificar los desafíos para reducir la tuberculosis (TB) en cárceles de Bolivia, Ecuador y Paraguay y recomendar vías para solucionarlos mediante intervenciones informativas.

Comunicación participativa para el control de la tuberculosis en cárceles de Bolivia, Ecuador y Paraguay

Palabras clave
Métodos. Se analizaron las dificultades para alcanzar dos metas centrales del control de la TB: el diagnóstico temprano de los casos positivos y la aplicación exitosa del tratamiento bajo supervisión directa de curso corto. Se obtuvieron datos (mediante entrevistas estructuradas en profundidad) y se convocaron grupos focales en las cárceles con más reclusos hombres en cada país. Entre los entrevistados y el grupo focal había directores de programas, personal administrativo, sanitario y de seguridad de las cárceles, así como reclusos que recibían o habían recibido tratamiento contra la TB y que habían participado como "pares" en los servicios de salud.

Resultados. Se detectaron obstáculos arraigados que impedían el control adecuado de la TB. Las actitudes estigmatizadoras y el escaso conocimiento sobre la TB entre los reclusos y el personal clave de las prisiones desestimulaban la búsqueda de diagnóstico y tratamiento en las cárceles. Los problemas sistémicos de los servicios de salud de las prisiones, junto con las insalubres condiciones de vida, la falta de coordinación entre los programas nacionales de TB y los sistemas de salud de las prisiones, y la insuficiente asignación de recursos sanitarios impidieron brindar una prevención adecuada y un cuidado eficaz de la TB.

Conclusión. Para eliminar las barreras al control eficaz de la TB en los sistemas carcelarios de Bolivia, Ecuador y Paraguay se requiere de un enfoque participativo de comunicación.

Comunicación en salud; poblaciones vulnerables; salud de grupos específicos; tuberculosis; prisiones; Bolivia; Ecuador; Paraguay. 